\title{
Research on Low-Carbon Development Pathways of China's Industrial Parks Under the Guidance of Big Data
}

\author{
Lin Xin ${ }^{1, *}, D u$ Zhehua $^{2}$ \\ ${ }^{1}$ Hubei Province Engineering Consulting Co., LTD., 430071 Wuhan, China \\ ${ }^{2}$ Wuhan Second Ship Design and Research Institute, 430205 Wuhan, China
}

\begin{abstract}
The Chinese government pledged to strive to peak carbon emission by 2030 and achieve carbon neutrality by 2060 . In the context of the industrial sector's deepening response to climate change and the overall promotion of green transformation, industrial parks have become the critical trouble-shooters in achieving scientific and precise targeted carbon emission reductions in the industrial sector during the "14th Five-Year Plan" period and even in the future. Based on big data analysis, this paper analyzed the carbon emission data of 213 national industrial parks. This paper identified challenges and opportunities underlying the low-carbon transition of China's industrial parks, and quantified decarbonization targets, pathways and potentials of the industrial parks towards 2035 and 2050. During 2015-2050, China's industrial parks are expected to reduce $\mathrm{CO}_{2}$ emission by 1.8 gigaton (dropped by more than $60 \%$ ) via industrial structure optimization, energy efficiency improvement, energy structure decarbonization, and carbon capture, utilization and storage; specifically, 0.8 and 1.0 gigaton of $\mathrm{CO}_{2}$ emission could be reduced during 20152035 and 2035-2050, respectively
\end{abstract}

\section{Introduction}

The $2{ }^{\circ} \mathrm{C}$ temperature control target set by the Paris Agreement has put forward urgent requirements for the low-carbon development of the global economy. Global climate change has become one of the major challenges threatening the sustainable development of mankind. The impact of COVID-19 has highlighted the need to rethink the harmonious coexistence of human development and ecosystems. As the world's largest carbon emitter, China has a great responsibility in tackling climate change. In September 2020, the Chinese government pledged to take stronger policies and measures to control $\mathrm{CO}_{2}$ emissions. China aims to peak $\mathrm{CO}_{2}$ emissions before 2030 and strive to achieve carbon neutrality before 2060. Achieving the mid- and longterm climate goals of carbon peaking and carbon neutrality has become a major strategy for China.

In 2017, China's industrial added value accounted for $34 \%$ of gross domestic product. Industrial energy consumption accounted for $66 \%$ of the total national energy consumption. It can be seen that industry is a key area for implementing greenhouse gas emission reduction. Industrial energy saving and carbon reduction play an important role in mitigating climate change. Industrial parks are the most important and extensive vehicle for China to build a green manufacturing system and implement the strategy of manufacturing power. Industrial parks undertake intensive industrial production activities and are also an important source of power for China's dual-cycle development.
The construction of industrial parks is a common phenomenon in global industrial development. Industrial parks are characterized by agglomeration of enterprises and sharing of infrastructure [1]. After more than 40 years of advancing development from point to area, from the coast to the inland, industrial parks have spread all over the country. Industrial parks have become important industrial production space and layout method. Industrial parks are also an important carrier for the development of industrialization and urbanization. According to different levels of industrial parks, they can be divided into national industrial parks, provincial industrial parks and other industrial parks. At present, there are 2543 national and provincial industrial parks in China. They contribute more than $50 \%$ of the national industrial output value. Achieving carbon peak in industrial parks through low-carbon transformation is not only the inherent requirement of high-quality development of industrial parks, but also plays a key role in the industrial sector's response to global climate change and implementation of global temperature rise control target.

\section{Methods and data}

\subsection{Green house gas accounting method based on life cycle perspective}

Greenhouse gas emission accounting has been very extensive at the national level $[2,3]$, regional level $[4,5]$

\footnotetext{
*orresponding author: 754726516@qq.com
} 
and city level [6]. However, at the park level, there are only a few case studies on greenhouse gas emission and emission reduction in industrial parks, such as Suzhou Industrial Park [7], Beijing Economic and Technological Development Zone [8], and Shenyang Economic and Technological Development Zone [9]. At present, greenhouse gas accounting method adopted by relevant research institutes in the parks is mainly from the perspective of consumption. They mostly follow accounting guidelines published by World Resources Institute. According to the different sources of greenhouse gas emissions, the guidelines divide emissions into ranges 1 to 3 .

In recent years, tracing the upstream and downstream links of industrial chain from the perspective of life cycle and identifying indirect greenhouse gas emissions has become a research hotspot. Implicit greenhouse gas emissions from energy production, material manufacturing and regional trade, for example, have attracted increasing attention [10]. At the same time, direct and indirect emissions into the scope of greenhouse gas accounting is conducive to objectively clarify the emission responsibility of the park and future reduction space.

\subsection{Evaluation method of park carbon emission reduction potential based on index decomposition}

According to "China Carbon Neutrality Comprehensive Report 2020" recently released by Energy Foundation, under the $2^{\circ} \mathrm{C}$ temperature control target, the total $\mathrm{CO}_{2}$ emissions of China's industrial sector in 2035 and 2050 will need to be reduced by $20 \% \sim 35 \%$ and $50 \% \sim 80 \%$ respectively compared with 2015 . From the perspective of industrial systems and energy systems, combined with supply-side and demand-side analysis, the carbon emission reduction path of industrial parks mainly covers the following aspects.

- Optimize the industrial structure and reduce the proportion of high-energy-consuming industries.

- Energy efficiency improvement involving technology saving and energy productivity improvement.

- Adjust energy structure to increase the proportion of wind energy, solar energy, hydrogen energy, biomass energy, industrial waste heat, domestic waste and sludge in energy consumption.

- Carbon Capture, Utilization, and Storage (CCUS).

Based on the above four carbon emission reduction paths, and fully considering the economic development scenarios of the park under different industrial growth rates, the study uses the index decomposition method to further quantify and identify the emission reduction effects of each path. In this study, logarithmic mean divisia index (LMDI) is used. It has the advantages of path independence and sum consistency [11], and has been widely used in policy research such as analysis of carbon emission driving force [12,13]. This study divides the time span from 2015 to 2050 as follows: the first phase takes 2015 as the base year and 2035 as the target year; the second phase takes 2035 as the base year and 2050 as the target year. Furthermore, LMDI decomposition method is used to quantitatively identify the carbon increase brought about by economic growth and the carbon emission reduction potential of the four emission reduction paths.

The decomposition of driving factors of $\mathrm{CO}_{2}$ emissions in industrial parks refers to Kaya formula, which can be decomposed into the form of multiplication of economic aggregates, energy consumption intensity, energy structure, energy carbon intensity and other factors [12], see equation (1). Among them, $C$ represents $\mathrm{CO}_{2}$ emissions (ten thousand tons), $C_{i}$ represents emissions of the $i$-th energy; $I A V$ is industrial added value (100 million yuan); $E I$ is energy intensity (ton of standard coal/ten thousand yuan); $E S_{i}$ represents energy structure, that is, the share of the $i$-th energy; $E F_{i}$ represents the life-cycle carbon emission factor of the $i$ th energy (ton/ton standard coal); $i=1 . .6$, which in turn represent coal, oil, natural gas, electricity, heat, and nonfossil energy (garbage, biomass and sludge, waste heat, wind, light, hydrogen, etc.).

$$
C=\sum_{i} C_{i}=\sum_{i} I A V \times E I \times E S_{i} \times E F_{i}
$$

LMDI decomposition method is adopted to decompose $\mathrm{CO}_{2}$ emission change from the base year $T_{0}$ to the target year $T$ into the sum of the changes caused by the above factors, as shown in Equation (2). Among them, $\Delta C_{I A V}, \Delta C_{E I}, \Delta C_{E S}$, and $\Delta C_{E F}$ respectively represent changes in $\mathrm{CO}_{2}$ emissions caused by industrial added value growth, energy intensity decline, energy structure optimization, and changes in carbon emission factors. $\triangle \mathrm{CEF}$ can be further decompositised to the change in carbon emissions caused by the increase of CCUS coverage and the decrease of grid carbon intensity, namely $\Delta C_{C C U S}$ and $\Delta C_{\text {Grid }}$.

$$
\begin{aligned}
& \Delta C=C_{T}-C_{T_{0}}=\sum_{i} \frac{C_{i}^{T}-C_{i}^{T_{0}}}{\ln C_{i}^{T}-\ln C_{i}^{T_{0}}} \times\left(\ln C_{i}^{T}-\ln C_{i}^{T_{0}}\right) \\
& =\sum_{i} \frac{C_{i}^{T}-C_{i}^{T_{0}}}{\ln C_{i}^{T}-\ln C_{i}^{T_{0}}} \times \ln \frac{I A V^{T}}{I A V^{T_{0}}}+\sum_{i} \frac{C_{i}^{T}-C_{i}^{T_{0}}}{\ln C_{i}^{T}-\ln C_{i}^{T_{0}}} \times \ln \frac{E I^{T}}{E I^{T_{0}}} \\
& +\sum_{i} \frac{C_{i}^{T}-C_{i}^{T_{0}}}{\ln C_{i}^{T}-\ln C_{i}^{T_{0}}} \times \ln \frac{E S_{i}^{T}}{E S_{i}^{T_{0}}}+\sum_{i} \frac{C_{i}^{T}-C_{i}^{T_{0}}}{\ln C_{i}^{T}-\ln C_{i}^{T_{0}}} \times \ln \frac{E F_{i}^{T}}{E F_{i}^{T_{0}}} \\
& =\Delta C_{I A V}+\Delta C_{E I}+\Delta C_{E S}+\Delta C_{E F} \\
& =\Delta C_{I A V}+\Delta C_{E I}+\Delta C_{E S}+\Delta C_{C C U S}+\Delta C_{\text {Grid }}
\end{aligned}
$$

Energy consumption intensity is the comprehensive energy consumption per unit of industrial added value, reflecting the dual role of industrial structure optimization and energy efficiency improvement. The reference value adopts "National Eco-industrial Demonstration Park Standard (HJ 274-2015)". Under the low-growth scenario, the average energy consumption intensity of industrial parks in 2035 will reach the level of ecological industrial parks. The energy consumption intensity level of the high-growth scenario is slightly higher than that of the low-growth scenario.

In terms of energy structure, the proportion of nonfossil energy such as household waste, biomass and sludge, waste heat, wind, light and hydrogen is expected to increase significantly. This study assumes that under 
the two scenarios, the proportion of domestic waste and biomass (including sludge) in 2035 will increase to $1 \%$ and $1.5 \%$, respectively, and remain unchanged until 2050. In both scenarios, the proportion of waste heat will increase from $0.7 \%$ to $2 \%$ from 2015 to 2035 . Under the high-growth scenario, wind power and photoelectricity will each take up $4.5 \%$ on average in industrial parks in 2035, while under the low-growth scenario, wind power and photoelectricity will each take up $3 \%$, which will remain unchanged until 2050.

\section{Results and discussion}

\subsection{Total carbon emissions from industrial parks}

Among the 2543 industrial parks, there are 218 nationallevel economic and technological development parks. They are a relatively mature and leading group in China's industrial parks, and they have good economic performance. The data availability and reliability of these parks are also high. In the previous research [14], basic data of 213 national economic development parks were collected. The total GDP of these 213 industrial parks reached 7.6 trillion yuan in 2015, accounting for $11 \%$ of the national GDP in the same year. The energy consumption of 213 national economic development parks in 2015 totaled 390 million tons of standard coal, accounting for $10 \%$ of the total national energy consumption in the same year[14]. Coal consumption accounted for $74 \%$ of total energy consumption, which clearly exceeded the share of coal consumption in China's industrial sector $(56 \%)$ in the same year [14]. The share of crude oil and natural gas is $36 \%$ and $8 \%$ respectively, ranking second and third place [14]. The diversity of energy consumption in the 213 parks is obvious. Unconventional energy sources such as waste heat, biomass, domestic garbage, coal gangue and industrial solid waste have been utilized to a certain extent. However, its total share is only $2 \%$.It shows that there is still much room for improvement in the development of low-carbon energy in the parks [14,15]. In 2015, the direct and indirect greenhouse gas emissions of 213 national economic development parks were 1.04 billion tons and 180 million tons of $\mathrm{CO}_{2}$ equivalent, respectively. Each accounted for $85 \%$ and $15 \%$ of total emissions [14]. It is urgent to clarify the carbon emission reduction path of industrial parks and promote effective carbon emission reduction measures.

\subsection{Carbon emission reduction potential in industrial parks}

In general, new increment of carbon emissions brought by the economic growth of parks in the future will still be very significant. However, it is possible to offset this and achieve a net reduction through four ways of reducing emissions. Industrial structure adjustment and energy efficiency improvement have the most significant carbon emission reduction potential. Increasing the share of non-fossil fuels and increasing the use of CCUS also offer considerable carbon reduction potential. The emission reduction effect of grid carbon intensity reduction is not obvious. From the perspective of time span, the emission reduction potential of industrial structure optimization, energy efficiency improvement, and energy structure optimization will be significantly reduced from 2035 to 2050 . This shows that by 2035 , the carbon emission reduction potential of these three aspects can basically be fully released. Long-term deep emission reductions need to rely mainly on the continuous promotion of system optimization in industrial production activities, regional optimization of the industrial layout, and end-targeted CCUS to further complete the overall carbon emission reduction target.

Further, carbon emission reduction potential of energy structure optimization is divided into six types of energy such as domestic waste, biomass and sludge, waste heat, wind, light and hydrogen. For specific base years and target years, the following values are adopted in this study as the weight of each energy's contribution to the total carbon emission reduction in the optimization of energy structure: the growth share of a certain energy $\div$ the total growth share of non-fossil energy $\times(1-$ the carbon emission factor of a certain energy $\div$ the carbon emission factor of coal). Further, the corresponding carbon emission reduction contributions caused by the increase in the proportion of six non-fossil energy sources are shown in Table 1.

Table 1. Carbon emission reduction contribution

\begin{tabular}{|c|c|c|c|c|}
\hline $\begin{array}{l}\text { Energy } \\
\text { variety }\end{array}$ & $\begin{array}{r}2015- \\
2035 L\end{array}$ & $\begin{array}{c}2015- \\
2035 H\end{array}$ & $\begin{array}{r}2035- \\
2050 L\end{array}$ & $\begin{array}{r}2035- \\
2050 H\end{array}$ \\
\hline Garbage & $3.0 \%$ & $2.2 \%$ & 0 & 0 \\
\hline $\begin{array}{l}\text { Biomass } \\
\text { and sludge }\end{array}$ & $7.8 \%$ & $5.8 \%$ & 0 & 0 \\
\hline Waste heat & $10.4 \%$ & $7.6 \%$ & 0 & 0 \\
\hline Wind power & $21.3 \%$ & $23.6 \%$ & 0 & 0 \\
\hline Photovoltaic & $18.9 \%$ & $20.9 \%$ & 0 & 0 \\
\hline $\begin{array}{c}\text { Hydrogen } \\
\text { energy }\end{array}$ & $38.5 \%$ & $39.8 \%$ & $100 \%$ & $100 \%$ \\
\hline
\end{tabular}

Note: $L$ represents low growth scenario. $H$ represents low growth scenario.

The result shows that the most significant contribution to carbon emission reduction is expected to be hydrogen energy, wind power and photovoltaic. The contribution rate of these three emissions reductions from 2015 to 2035 can reach $79 \%$ to $84 \%$ in total. In particular, hydrogen energy can contribute $100 \%$ of emission reduction potential from 2035 to 2050 . This is the most potential measure for deep emission reduction by adjusting energy structure. Unconventional energy sources, such as garbage, biomass, sludge and waste heat, do not contribute significantly due to their small proportion in the energy structure. Considering the conservative parameter values used in this study, the share of these three types of energy sources will not increase further from 2035 to 2050 . If the recovery and utilization of these three types of energy is greatly increased in the future, and the incinerator technology is improved to reduce the coal blending ratio, its contribution to carbon emission reduction is expected to increase further. 


\section{Conclusion and suggestion}

\subsection{Main conclusion}

The challenges and opportunities of reducing greenhouse gas emissions in China's industrial parks coexist. Parks are facing the double pressure of rapidly promoting the transformation of low-carbon energy and green industrial development. In the short term, it is necessary to change the situation where the industrial sector and energy infrastructure are highly dependent on fossil fuels.

The contribution of greenhouse gas emission reduction in China's industrial parks to $2^{\circ} \mathrm{C}$ temperature control target can be expected. Parks still have huge potential for emission reduction in terms of industrial structure, energy structure, energy saving level, and carbon capture. Through the elimination or replacement of outdated production capacity, energy efficiency improvement, waste heat recovery and utilization, etc., the emission reduction task in the short term (2015-2035) can be basically achieved. With the gradual coverage of fossil fuel facilities by CCUS and the extensive use of zero-carbon hydrogen energy in industrial processes, China's industrial parks' deep emission reduction task for 2050 or 2060 is also expected to be achieved.

\subsection{Suggestion}

Based on the above research, the following policy suggestions are proposed for deepening low-carbon development of industrial parks.

- Develop systematic, standardized, and standard industrial park greenhouse gas emission accounting methods and toolkits. It is recommended to develop and compile the greenhouse gas accounting framework and implementation rules for industrial parks based on the life cycle method, and develop an online accounting toolkit.

- Formulate roadmaps for the classification of lowcarbon development in industrial parks. It is necessary to formulate a roadmap for coordinated control of greenhouse gases and multi-pollutants in China's industrial parks to support them in their battle against pollution and green and low-carbon transformation.

- Carry out the construction of carbon peak demonstration pilot parks. Combining with the currently ongoing projects of national eco-industrial demonstration parks, green parks, and circular transformation pilot parks, a number of carbon peak demonstration pilot parks will be formed during the "14th Five-Year Plan" period.

\section{References}

1. M.T. Peddle, Economic Development Quarterly, 7, 107 (1993)

2. Z. Liu, D.B. Guan, W. Wei, Nature, 524, 335 (2015)

3. D.B Guan, J. Meng, D.M. Reiner, Nature Geoscience, 11, 551 (2018)
4. H.T. Bai, Y.X. Zhang, H.Z. Wang, Environmental Science \& Technology, 48, 2541 (2014)

5. Y. Shan, D.B Guan, H.R. Zheng, Scientific Data, 5, $170201(2018)$

6. B.F. Cai, H.X. Guo, L.B. Cao, Journal of Cleaner Production, 178, 890 (2018)

7. L.X.Liu, B. Zhang, J. Bi, Energy Policy, 46, 301 (2012)

8. W. Liu, J.P. Tian, L.J. Chen, Journal of Cleaner Production, 66, 384 (2014)

9. H.J. Dong, Y. Geng, F.M. Xi, Energy Policy, 57, 298(2013)

10. R. Kumanayake, H.B. Luo, N. Paulusz, Energy and Buildings, 166, 250 (2018)

11. B.W. Ang, Energy Policy, 33, 867 (2005)

12. J. Meng, Z.F. Mi, D.B. Guan, Nature Communications, 9, 1871 (2018)

13. L.C. Liu, Y. Fan, G. Wu, Energy Policy, 35, 5892 (2007)

14. Y. Guo, J.P. Tian, N. Zang, Environmental Science \& Technology, 52, 7754 (2018)

15. W.Q. Hu, Y. Guo, J.P. Tian, Resources, Conservation and Recycling, 161, 104992 (2020) 